\title{
KESADARAN BERLALU LINTAS MAHASISWA PENDIDIKAN TEKNIK MESIN UNIVERSITAS SARJANAWIYATA TAMANSISWA YOGYAKARTA
}

\author{
Rabiman $^{1 *}$ dan Nurcholish Arifin Handoyono ${ }^{1}$ \\ ${ }^{1}$ Pendidikan Teknik Mesin FKIP UST \\ *Email: rabimanust@yahoo.com
}

\begin{abstract}
ABSTRAK
Penelitian ini bertujuan untuk mengetahui: 1) tingkat kesadaran berkendara aman (safety riding) pada mahasiswa Program Studi Pendidikan Teknik Mesin Universitas Sarjanawiyata Tamansiswa; dan 2) tingkat berkendara secara ekonomis (eco riding) pada mahasiswa Program Studi Pendidikan Teknik Mesin Universitas Sarjanawiyata Tamansiswa. Jenis penelitian yang digunakan adalah deskriptif. Populasi penelitian adalah seluruh mahasiswa Program Studi Pendidikan Teknik Mesin dengan jumlah 478 mahasiswa. Sampel diambil menggunakan teknik stratified random sampling ditemukan jumlah 199 mahasiswa. Instrumen yang digunakan adalah tes pilihan ganda untuk mengukur tingkat kesadaran berkendara aman (safety riding) dan berkendara secara ekonomis (eco riding). Teknik analisis data menggunakan statistik deskriptif. Hasil penelitian menunjukan bahwa: 1) Tingkat kesadaran berkendara aman (safety riding) pada mahasiswa Program Studi Pendidikan Teknik Mesin Universitas Sarjanawiyata Tamansiswa dikategorikan sangat tinggi dengan nilai rata-rata 24,78; dan 2) Tingkat berkendara secara ekonomis (eco riding) pada mahasiswa Program Studi Pendidikan Teknik Mesin Universitas Sarjanawiyata Tamansiswa dikategorikan sangat tinggi dengan nilai rata-rata 6,85 .
\end{abstract}

Kata kunci: safety riding, eco riding

\section{TRAFFIC AWARENESS OF MECHANICAL ENGINEERING EDUCATION STUDENTS OF UNIVERSITAS SARJANAWIYATA TAMANSISWA YOGYAKARTA}

\begin{abstract}
This study aimed to determine: 1) The level of safety riding for students of Mechanical Engineering Education; and 2) The level of eco riding for students of Mechanical Engineering Education. The type of research used is descriptive. The research population was all students of Mechanical Engineering Education at The Faculty of Teacher Training and Education at Universitas Sarjanawiyata Tamansiswa. The sample was taken using the Stratified random sampling technique which found 199 students. The instrument used is a multiple choice tests to measure the level of safety riding and the level of eco riding. The data analysis technique uses descriptive statistics. The result results showed that: 1) The level of safety riding for students of Mechanical Engineering Education was categorized very hight with an average value of 24,78; and 2) 1) The level of eco riding for students of Mechanical Engineering Education was categorized very hight with an average value of 6,85.
\end{abstract}

Keywords: safery riding, eco riding 


\section{PENDAHULUAN}

Indonesia merupakan salah satu negara berkembang dengan jumlah penduduk pada tahun 2010 sebesar 238.518.800 jiwa dan diperkirakan jumlah ini akan menjadi 252.164.800 jiwa pada tahun 2014 dan 261.890.900 jiwa pada tahun 2017 (www.bps.go.id). Dengan jumlah penduduk tersebut, Indonesia menduduki peringkat keempat jumlah penduduk terbanyak di dunia yaitu menyumbang 3,5\% dari jumlah penduduk dunia.

Dengan pola pertumbuhan penduduk makin hari makin cepat, maka penggunaan transportasi akan semakin meningkat pula. Jumlah kendaraan bermotor yang melintas di jalan setiap harinya sangat banyak, bahkan melebihi kapasitas jalan yang tersedia. Peningkatan jumlah kendaraan ini tidak lepas dari tingginya mobilitas masyarakat yang mendorong kepadatan lalu lintas sering terjadi, baik barang maupun manusia. Hal ini juga terjadi di DIY dimana jumlah kendaraan hingga tahun 2015 tercatat berjumlah 2,2 juta unit yang didominasi kendaraan roda dua dengan jumlah 1,9 juta dengan pertumbuhan 7,9 persen per tahun. Sementara untuk roda empat yakni mobil penumpang berjumlah 206,7 ribu unit. Dari tahun 2010 hingga 2015, pertumbuhan mobil mencapai 10,7 persen (http://jogja.tribunnews.com).

Melihat perkembangan yang ada dari kepadatan lalu lintas tersebut, semakin banyak ditemukan fakta yang menunjukkan bahwa jalan raya justru menjadi wadah pembunuhan manusia. Masalah seperti ini perlu diperhatikan dari berbagai kalangan masyarakat maupun pemerintah agar angka kecelakan lalu lintas dapat ditekan seminimal mungkin. Faktanya, angka kecelakan lalu lintas malah terus meningkat setiap tahunnya di kota-kota besar tidak terkecuali di Kota Daerah Istimewa Yogyakarta (DIY). Peningkatan angka kecelakaan di Kota DIY yang dapat dilihat pada pada tabel 1. Tabel 1 menunjukkan bahwa dari tahun 2014 ke 2015 jumlah angka kecelakaan pada jenis luka ringan telah mengalami peningkatan sebesar 837 korban. Pada jenis luka berat dan meninggal sama-sama mengalami penurunan yaitu masing-masing sebesar 144 dan 83 korban. Secara keseluruhan kecelakaan yang terjadi pada tahun 2015 telah bertambah sebanyak 640 korban dari tahun sebelumnya. 
Tabel 1. Angka Kecelakaan di Kota DIY

\begin{tabular}{ccc} 
Jenis & \multicolumn{2}{c}{ Tahun } \\
\cline { 2 - 3 } Kecelakaan & $\mathbf{2 0 1 4}$ & $\mathbf{2 0 1 5}$ \\
\hline Luka ringan & 5.115 & 5.952 \\
Luka berat & 155 & 41 \\
Meninggal & 485 & 402 \\
\hline Total & $\mathbf{5 . 7 5 5}$ & $\mathbf{6 . 3 9 5}$ \\
\hline
\end{tabular}

(Sumber: BPS, 2015: 57-59)

Keadaan di atas merupakan cerminan dari perilaku tertib berlalu lintas yang rendah di DIY. Hal ini dibuktikan oleh temuan jumlah pelanggar lalu lintas sebanyak 29.074 pelanggar pada tahun 2014 di Kota DIY. Jumlah pelanggaran ini menduduki peringkat kedua pelanggar terbanyak setelah Sleman se-DIY (BPS Provinsi Daerah Istimewa Yogyakarta, 2015: 218).

Kasus yang ditemukan pada pelanggaran lalu lintas ini disebabkan oleh berbagai macam pelanggaran. Irwan (2016) dalam website mengungkapkan beberapa pelanggaran lalu lintas yang sering terjadi di DIY antara lain: (1) menerobos lampu merah; (2) tidak menggunakan helm; (3) tidak menyalakan lampu kendaraan; (4) tidak membawa surat kelengkapan berkendara; (5) melawan arus (contra flow); (6) melanggar rambu-rambu lalu lintas; (7) penggunaan kendaraan yang tidak memperhatikan aspek keselamatan; (8) tidak menggunakan spion; dan (9) berkendara melewati trotoar. (http://www.lenterajogja.com).

Setidaknya pelanggaran di atas memang sering dijumpai di jalan-jalan perkotaan khususnya Kota DIY. Buruknya perilaku tertib berlalu lintas dapat disebabkan oleh faktor kesadaran berkendara aman (safety riding) bagi kalangan masyarakat. Safety riding merupakan usaha yang dilakukan dalam meminimalisir tingkat bahaya dan memaksimalkan keselamatan dalam berkendara. Tingginya angka kecelakan merupakan salah satu indikator bahwa kesadaran berkendara aman di kalangan masyarakat Kota DIY masih rendah, sehingga perlu pembenahan dari berbagai pihak. Hasil penelitian dari Eni Mahawati dan Jaka Prasetya (2013) memperkuat pernyataan ini yang menyimpulkan bahwa safety riding perlu dirancang pada remaja dalam upaya eliminasi gangguan kesehatan dan kecelakaan lalu lintas

Poin utama dalam kesadaran berkendara aman tercantum dalam UU No. 22 Th. 2009 tentang Lalu Lintas dan Angkutan Jalan, antara lain seperti: (1) kelengkapan kendaraan bermotor; (2) kelengkapan kaca spion wajib ada 2 (dua) buah di kiri dan kanan; dan (3) kelengkapan lampu depan, rem, riting kiri-kanan, dan klakson. Pada saat ini masih banyak 
masyakarat yang melakukan pelanggaran sebagaimana yang telah diatur dalam UU di atas. Hal ini semakin menguatkan bahwa rendahnya kesadaran berkendara aman di kalangan masyakarat.

Faktor yang tidak kalah pentingnya selain kesadaran berkendara aman untuk keselamatan berkendara dan mengurangi resiko kecelakaan perlu diketahui juga tentang cara berkendara yang ekonomis (eco riding). Konsumsi bahan bakar di Indonesia terus meningkat setiap tahunnya. Direktur pemasaran Pertamina, M Iskandar mengatakan total konsumsi semua produk BBM pada semester pertama tahun 2017 mencapai 32,6 juta kilo liter (kl), sementara konsumsi pada tahun 2016 sebesar 31,7 juta kilo liter (kl) untuk semua produk BBM (http://industri.bisnis.com/read/20170816/44/681587/konsumsi-bbmparuh-pertama-

2017memben). Humas SKK Migas Dian sulistiawan mengatakan tingkat konsumsi bahan bakar minyak secara nasional mencapai 1,6 juta barel per hari, sedangkan kemampuan produksi hanya 834 ribu barel per hari (https://m.wartaekonomi.co.id/berita152820/skk-migas-masyarakat indonesia-rakuskonsumsi-bbm.html).

Ditengah konsumsi dan harga bahan bakar yang kian meningkat, berkendara secara ekonomis (eco riding) harus diperhatikan untuk dapat lebih efisien dalam menggunakan bahan bakar Berkendara secara ekonomis dapat menyumbang penurunan konsumsi bahan bakar. Meskipun demikian, masih banyak penggunaan dan modifikasi sepeda motor dengan cara yang tidak benar dapat menyebabkan boros bahan bakar. Banyak pengendara yang tidak sadar, memutar gas berulang-ulang membuat bahan bakar menguap percuma. Tidak hanya itu, perilaku ini juga menimbulkan polusi suara yang tidak perlu dan mengganggu pengendara lain. Banyak juga pengendara yang mengganti komponen standar motor seperti knalpot dan karburator, yang dapat menyebabkan pasokan bensin menjadi deras (https://www.google.co.id/amp/sm.liputan6.com/amp/2093731/waspada5-modifikasi-ini-

bikin-motor-borosbensin).

Agar masyarakat menyadari pentingya dalam berperilaku berlalu lintas yang baik, maka penelitian ini perlu diadakan. Penelitian ini akan mengungkapkan secara rinci gambaran sejauh mana kesadaran berkendara aman (safety riding) dan berkendara secara ekonomis (eco riding) Mahasiswaa Prodi Pendidikan Teknik Mesin Universitas Sarjanawiyata Tamansiswa sebagai calon guru SMK. Rutter,et.al. (2007) menyatakan bahwa kecelakaan lalu lintas adalah penyebab utama kematian di kalangan anak muda, berusia 15-24 tahun. Pernyataan ini berati penyumbang pelaku terbanyak dari kecelakaan adalah dari pelajar, oleh karena itu Sebagai calon guru SMK para mahasiswaa diharapkan dapat menjadi contoh yang baik dalam berlalu lintas. Paparan dari hasil penelitian ini diharapkan dapat menumbuhkan rasa kesadaran 
masyakarat dalam menaati peraturan lalu lintas khususnya bagi para Mahasiswa Prodi Pendidikan Teknik Mesin Universitas Sarjanawiyata Tamansiswa, sehingga angka kecelakaan dapat ditekan.

\section{Kesadaran Berkendara Aman (Safety Riding)}

Kesadaran adalah sikap seseorang yang secara sukarela menaati semua peraturan dan sadar akan tugas dan tanggung jawabnya (Malayu Hasibuan, 2012: 193). Kemudian menurut Kamus Besar Bahasa Indonesia, "kesadaran adalah keinsafan, keadaan mengerti, hal yang dirasakan atau dialami oleh seseorang." Kedua arti ini memiliki makna bahwa pada diri seorang secara sadar atau tidak sadar memiliki rasa tanggung jawab yang harus dijalankan. Kesadaran yang dimiliki oleh seseorang pada konteks ini adalah berkendara aman (safety riding). Inti dari safety riding itu sendiri adalah mengutamakan keselamatan diri dan juga pengguna jalan lain (Marye Agung Kusmagi, 2010: 40).

Safety riding dapat diupayakan melalui ketertiban berlalu lintas dijalan. Aturan tertib berlalu lintas telah tercantum dalam Peraturan Pemerintah Republik Indonesia Nomor 43 Tahun 1993 tentang Prasarana dan Lalu Lintas Jalan yang dapat diuraikan sebagai berikut:

a. Penggunaan jalur jalan (Pasal 51)

1) Tata cara berlalu lintas mengambil jalur jalan sebelah kiri.

2) Penggunaan selain jalur kiri apabila:

a) Melewati kendaraan di depan.

b) Ditunjuk/ditetapkan petugas yang berwenang.

b. Tata cara melewati (Pasal 52)

Pengemudi yang akan melewati kendaraan lain harus:

1) Harus memiliki pandangan yang bebas dan menjaga ruang yang cukup bagi kendaraan yang dilewatinya.

2) Mengambil lajur/jalur sebelah kanan kendaraan yang dilewatinya.

3) Dalam kendaraan tertentu boleh sebelah kiri, bila:

a) Lajur kanan macet.

b) Bermaksud belok kiri.

c. Pengemudi dilarang melewati (Pasal 55)

1) Kendaraan lain di persimpangan atau persilangan sebidang.

2) Kendaran lain yang sedang memberikan kesempatan menyeberang kepada pejalan kaki atau pengendara sepeda.

d. Pengemudi yang akan dilewati kendaraan lain wajib (Pasal 56) 


\section{Rabiman dan Nurcholish Arifin Handoyono}

1) Memberikan ruang gerak yang cukup bagi kendaraan yang akan melewati.

2) Memberikan kesempatan/menjaga kecepatan agar dapat melewati dengan aman.

e. Tata cara berpapasan (Pasal 57 dan 58)

1) Berpapasan di jalan yang tidak ada pemisah harus memberikan ruang gerak yang cukup di sebelah kanan kendaraan.

2) Bila ada rintang di depan, dahulukan kendaraan dari arah berlawanan.

3) Pada tanjakan/menurun yang tidak memungkinkan bagi kendaran untuk saling berpasasan, pengemudi kendaraan yang arahnya turun harus memberi kesempatan jalan kepada kendaraan yang menanjak

f. Tata cara membelok (Pasal 59)

1) Pengemudi yang akan membelok/berbalik arah atau berpindah jalur harus:

a) Mengamati situasi di depan, samping, dan belakang.

b) Memberi isyarat dengan lampu/lengan

2) Pengemudi dapat langsungn belok kiri pada setiap persimpangan jalan kecuali ditentukan lain oleh rambu atau alat pemberi isyarat lalu lintas.

g. Memperlambat kendaraan (Pasal 60)

1) Pengemudi harus memperlambat kendaraan apabila akan melewati:

a) Kendaraan umum yang sedang menaikkan/menurunkan penumpang.

b) Kendaraan tidak bermotor yang ditarik hewan, hewan yang ditunggangi atau digiring.

2) Pengemudi dilarang melewati:

a) Kendaraan lain di persimpangan/persilangan sebidang dengan kereta api.

b) Kendaraan yang sedang memberi kesempatan menyeberang kepada pejalan kaki atau sepeda.

h. Posisi kendaraan di jalan (Pasal 61)

1) Pada jalur dua atau lebih lajur searah, kendaran berkecepatan lebih rendah dari pada kendaraan lain harus mengambil lajur kiri.

2) Perpindahan lajur harus memperhatikan situasi kendaraan di depan, samping, dan belakang serta memberikan isyarat lampu penunjuk arah.

3) Jika jalur dilengkapi rambu-rambu dan atau marka petunjuk kecepatan, maka kendaraan harus berada pada lajur sesuai kecepatannya.

i. Hak utama pada persimpangan dan perlintasan sebidang (Pasal 63)

1) Pada persimpangan tidak dengan APILL pengemudi wajib memberikan hak utama kepada: 
a) Kendaraan yang datang dari arah depan dan/atau cabang persimpangan lain jika dinyatakan dengan rambu/marka.

b) Kendaraan dari jalan utama apabila pengemudi datang dari jalan lebih kecil/gang/perkarangan.

c) Kendaraan yang datang dari arah cabang persimpangan sebelah kirinya apabila cabang persimpangan 4 atau lebih dan sama besar.

d) Kendaraan yang datang dari arah cabang sebelah kirinya di persimpangan 3 yang tegak lurus.

e) Kendaraan yang datang dari arah cabang persimpangan yang lurus pada persimpangan 3 tegak lurus.

2) Pada persimpangan dengan bundaran, hak utama pada kendaraan yang telah berapa di seputaran bundara.

3) Pada persilangan sebidang dengan jalan rel kereta api pengemudi harus:

a) Mendahulukan kereta api.

b) Memberikan hak utama kepada kendaraan yang lebih dahulu melintasi rel.

j. Berhenti dan parkir (Pasal 66)

1) Setiap jalan dapat digunakan sebagai tempat berhenti/parkir apabila tidak ada rambu, marka atau tanda lain atau di tempat tertentu seperti:

a) Sekitar tempat penyeberangan pejalan kaki/sepeda.

b) Pada jalur khusus pejalan kaki.

c) Pada tingkungan.

d) Di atas jembatan.

e) Dekat persimpangan/perlintasan kereta api.

f) Depan pintu keluar masuk pekarangan.

g) Pada tempat yang dapat menutupi APILL.

h) Dekat keran pemadam kebakaran atau sumber air sejenis.

2) Kendaraan berhenti/parkir dalam keadaan darurat wajib memasang segitiga pengaman, lampu isyarat bahaya atau isyarat lainnya.

k. Peringatan dengan bunyi (Pasal 71)

1) Isyarat peringatan dengan bunyi (klakson) digunakan apabila:

a) Diperlukan untuk keselamatan.

b) Melewati kendaraan bermotor lain.

2) Isyarat peringatan dengan bunyi (klakson) dilarang: 
a) Pada tempat tertentu dinyatakan dengan rambu.

b) Bunyi yang dikeluarkan tidak sesuai persyaratan teknis dan laik jalan kendaaran bermotor.

1. Penggunaan lampu (Pasal 73)

1) Pengemudi kendaraan bermotor di malam hari/waktu gelap wajib menyalakan lampu yang meliputi:

a) Lampu utama dekat.

b) Lampu posisi depan dan belakang.

c) Lampu tanda nomor kendaraan.

d) Lampu batas bagi kendaraan tertentu.

2) Pengemudi kendaraan bermotor dilarang:

a) Menyalakan/menggunakan lampu-lampu selain yang diwajibkan kecuali tidak mengganggu pemakai jalan.

b) Menyalakan lampu jauh waktu berpapasan.

c) Menutup lampu penunjuk arah, lampu mundur dan lampu isyarat peringatan.

d) Menyalakan lampu peringatan berwarna biru atau merah.

m. Perilaku pengemudi terhadap pejalan kaki (Pasal 84)

Pengemudi kendaraan bermotor wajib mengutamakan keselamatan pejalan kaki:

1) Yang berada/berjalan pada bagian jalan untuk pejalan kaki.

2) Yang akan/sedang menyeberang jalan.

n. Pejalan kali (Pasal 91)

1) Berjalan pada fasilitas untuk penjalan kaki/paling kiri.

2) Paling kiri bila mendorong kereta dorong.

3) Menyeberang di tempat yang ditentukan, bila tidak ada menyeberang di tempat yang menjamin keselamatan dan kelancaran lalu lintas.

4) Rombongan pejalan kaki menggunakan lajur paling kiri.

Seseorang dalam berkendara aman idealnya harus memiliki tingkat keamanan yang cukup baik bagi dirinya sendiri maupun bagi orang lain agar dapat terhindar dari kecelakaan lalu lintas (jnc.000s-space.com). Agar terjamin keselamatan di jalan, maka penerapan safety riding ini telah diatur dalam UU Nomor 22 Tahun 2009 tentang Lalu Lintas dan Angkutan Jalan. Pada UU lalu lintas disebutkan bahwa salah satu syarat kendaraan laik jalan adalah adanya komponen pendukung, yaitu: (a) pengukur kecepatan (spedoometer); (b) kaca spion; (c) penghapus kaca kecuali sepeda motor; (d) klakson; (e) spakbor; dan (f) bumper kecuali sepeda motor. Selain 
tercantum pada UU lalu lintas, Arizona (2013) juga merumuskan aturan safety riding yang meliputi: (a) kaca spion wajib ada 2 (kanan dan kiri); (b) lampu dan sein; (c) SIM dan STNK; (d) plat nomer; dan (e) perlengkapan safety riding.

Pengendara yang memiliki kesadaran berkendara aman maka akan selalu memperhatikan kondisi kendaraannya yang meliputi;

a. Pengukur kecepatan (spedoometer)

Speedometer merupakan alat ukur yang sangat penting untuk memantau kondisi sebuah kendaraan termasuk pada sepeda motor. Speedometer terletak pada bagian paling atas pada sepeda motor. Speedometer dibuat sedemikian rupa agar pengendara dapat melihat dengan jelas dan memudahkan dalam pembacaannya. Speedometer menyajikan berbagai instrumen dan indikator yang menunjukkan berbagai komponen atau kondisi kendaraan, baik pada saat berhenti maupun berjalan.

b. Kaca spion

Pada semua pengendara terdapat titik buta (blind spot), khususnya pada jarak pandang samping dan belakang pengendara. Untuk mengatasi hal ini agar dapat meminimalisir kemungkinan kecelakaan, maka diperlukan kaca spion. Kaca spion berfungsi untuk memastikan kondisi aman ketika pengendara hendak berbelok atau menyusul kendaraan lain. Dengan adanya kaca spion, pengendara dapat memastikan bahwa tidak ada objek bergerak dari arah belakang yang dapat menimbulkan benturan. Sesuai UU lalu intas, pada sepeda motor harus memiliki 2 spion yang terpasang pada sebelah kanan dan kiri.

c. Klakson

Pada umumnya klakson merupakan perlengkapan yang melekat pada kendaraan bermotor. Klakson diibaratkan sebagai alat komunikasi antar pengendara yang satu dengan yang lainnya. Klakson digunakan saat pengendara hendak memberi isyarat kepada pengendara yang lain untuk keselamatan dan keamanan kedua belah pihak, misalnya ketika hendak mendahului, meminta ruang jalan, dan sebagainya.

d. Spakbor

Fungsi utama dari pemasangan spakbor adalah untuk melindungi pengendara atau penumpang dari cipratan air apabila sedang hujan atau saat melewati genangan air. Agar spakbor dapat berfungsi dengan bagaimana semestinya maka spakbor memiliki posisi menjorok ke luar dibandingkan lampu belakang. Mengganti atau memotong spakbor akan merugikan diri sendiri dan orang lain karena ketika berkendara dalam kondisi hujan kotoran 
roda akan mengenai punggung diri sendiri dan pengendara yang berada dibelakangnya. Hal ini tentunya akan mengurangi keselamatan dan keamanan berkendara.

e. SIM dan STNK

Surat Ijin Mengemudi (SIM) berfungsi untuk mengetahui kelayakan seseorang dalam mengendarai suatu kendaraan. Seseorang dikatakan layak mengendarai sepeda motor jika memiliki SIM C. Surat Tanda Nomor Kendaraan (STNK) berfungsi untuk mengetahui spesifikasi kendaraan yang digunakan. Pada saat mengendarai sepeda motor pengendara wajib membawa SIM C dan STNK.

f. Plat nomor

Plat nomor merupakan salah satu jenis indentifikasi kendaraan bermotor. Plat nomor harus dipasang dengan benar yaitu pada bagian paling depan dan belakang sepeda motor, sehingga dapat dilihat dengan jelas oleh pengguna jalan. plat nomor yang dipasang hendaknya asli yang dikeluarkan dari kepolisian.

g. Perlengkapan safety riding

Pemilihan perlengkapan safety riding yang tepat sangat penting karena dapat melindungi dan membantu untuk terlihat oleh pengguna jalan lain. Perlengkapan safety riding meliputi: helm, pelindung mata/kaca mata dan pelindunng wajah/masker, pakaian pelindung seperti jaket, sepatu, dan sarung tangan.

Undang-undang No. 22 Tahun 2009 pasal 48 ayat 1 mengatakan bahwa setiap kendaraan bermotor yang dioperasikan di jalan harus memenuhi persyaratan teknis dan laik jalan. Berikut adalah pemeriksaan persyaratan teknis sebelum berkendara:

a. Roda dan ban

Memeriksa kondisi ban, memastikan keadaan ban dalam kondisi baik dan aman untuk digunakan. Memastikan kondisi ban terbebas dari benda asing seperti paku dan benda yang dapat merusak ban. Memastikan kondisi roda dalam keadaan baik.

b. Alat kendali

Memeriksa bagian tuas seperti tuas rem, kopling dan pemindah gigi perseneling (untuk motor manual). Memastikan dapat bekerja dengan nomal, tidak ada retak, bengkok atau patah.

c. Oli dan fluida

Memastikan oli dan fluida terisi sesuai petunjuk dan ukuran, termasuk pengecekan selang dari kebocoran.

d. Chasis 
Memeriksa kondisi chasis, memastikan dalam keadaan baik, tidak ada retak atau patah serta memeriksa shock absorber, mengatur posisi spion dan kekencangan rantai.

e. Lampu dan elektrikal

Memeriksa aki, lampu dekat, lampu jauh, penunjuk arah dan kabel kabel, memastikan dalam keadaan baik.

f. Surat tanda nomor kendaraan

Undang-undang No. 22 Tahun 2009 pasal 68 menyebutkan bahwa setiap kendaraan bermotor yang dioperasikan di jalan wajib dilengkapi dengan Surat Tanda Nomor Kendaraan Bermotor dan Tanda Nomor Kendaraan Bermotor.

\section{Berkendara Ekonomis (Eco Riding)}

Eco Riding merupakan teknik berkendara yang hemat bahan bakar, tujuannya tak hanya mampu menghemat rasio konsumsi bahan bakar tetapi juga dapat menjaga umur komponen mesin tetap optimal (https://otomotifnet.gridoto.com/read/02114923/). Dari uraian di atas dapat disimpulkan bahwa dengan eco riding pengendara sepeda motor dapat menghemat konsumsi bahan bakar sekaligus menjaga komponen mesin agar berumur panjang. Terdapat 2 hal yang dapat mempengaruhi konsumsi bahan bakar yaitu cara mengendarai sepeda motor dan pemeriksan/perbaikan sepeda motor agar penggunaan bahan bakar lebih efisien.

a. Cara bekendara yang dapat menghemat bahan bakar (PT YIMM, 2012: 6-4):

1) Tarik gas secara perlahan, pada saat melakukan percepatan.

2) Jangan mengoprasikan mesin dengan putaran tinggi jika tidak ada beban

3) Matikan mesin jika berhenti terlalu lama pada jalanan yang macet dan perlintasan kereta api dan sebagainya.

b. Pemeriksaan dan perbaikan sepeda motor agar penggunaan bahan bakar lebih efisien (http://www.modifikasi.co.id/2013/15)

1) Menggunakan komponen standar pabrikan sepeda motor. Seperti karburator dan komponen lain yang berhubungan dengan pasokan bahan bakar

2) Melakukan penyetelan katup

Pada sepeda motor 4 tak, penyetelan katup dapat dilakukan untuk menghemat bahan bakar dengan cara merapatkan setelan katup sepeda motor. Dengan merapatkan setelan katup sepeda motor maka penggunaan bahan bakar akan lebih efisien karena tidak ada bensin yang rembes.

3) Membuat manifold berkisi-kisi 
Bentuk manifold yang berkisi-kisi akan membuat campuran bahan bakar dan udara semakin homogen sehingga pembakaran akan menjadi lebih sempurna

4) Menggunakan oli mesin yang berkualitas

Dengan menggunakan oli yang berkualitas dapat mengurangi suhu mesin dan juga membuat dapur pacu menjadi lebih ringan sehingga konsumsi bahan bakar menjadi efisien.

5) Meningkatkan kompresi ruang bakar mesin

Semakin tinggi kompresi mesin maka bahan bakar yang akan masuk ke dalam silinder akan terbakar sempurna sehingga tidak ada bahan bakar yang tebuang sia-sia

6) Melakukan servis rutin karburator dan injektor

Service rutin harus dilakukan untuk menjaga injektor maupun karburator agar tetap bersih dan dapat bekerja secara optimal sehingga bahan bakar terpakai secara efisien

\section{METODE}

Jenis penelitian ini adalah deskriptif. Penelitian ini dilaksanakan di Program Studi PTM dengan populasi seluruh mahasiswa program studi PTM dengan jumlah 478 mahasiswa. Sampel diambil menggunakan teknik stratified ramdom sampling ditemukan jumlah 199 mahasiswa. Ukuran sampel diambil berdasarkan formulasi yang dikemukakan oleh Isaac dan Michael dengan taraf kesalahan 5\%, sehingga didapatkan distribusi sampel penelitian seperti tercantum pada tabel 2. Teknik pengumpulan data menggunakan tes pilihan ganda untuk mengukur tingkat kesadaran berkendara aman (safety riding) dan (eco riding). Uji validitas, reliabilitas, uji daya beda, dan tingkat kesukaran dihitung menggunakan aplikasi anates.

Teknik analisis data menggunakan statistik deskriptif dengan mengacu pada Rumus kriteria kurva normal (Anas Sudjiono, 2009: 329) dengan ketentuan sebagai berikut:

$$
\begin{array}{ll}
(\mathrm{M}+1,5 \mathrm{SD})<\bar{x}<\text { skor maksimal } & =\text { sangat tinggi } \\
(\mathrm{M}+0,5 \mathrm{SD})<\bar{x}<(\mathrm{M}+1,5 \mathrm{SD}) & =\text { tinggi } \\
(\mathrm{M}-0,5 \mathrm{SD})<\bar{x}<(\mathrm{M}+0,5 \mathrm{SD}) & =\text { sedang } \\
(\mathrm{M}-1,5 \mathrm{SD})<\bar{x}<(\mathrm{M}-0,5 \mathrm{SD}) & =\text { rendah } \\
\text { skor minimal ideal }<\bar{x}<(\mathrm{M}+1,5 \mathrm{SD}) & =\text { sangat rendah }
\end{array}
$$

Keterangan:

$\bar{x} \quad=$ Rata-rata hitung

$\mathrm{M} \quad=$ Rata-rata ideal 
$\mathrm{SD} \quad=$ Standar deviasi ideal

Nilai M dan SD dapat dicari dengan rumus sebagai berikut:

$\mathrm{M} \quad=0,5 \mathrm{x}($ skor maksimal ideal + skor

minimal ideal

$\mathrm{SD} \quad=0,167 \times($ skor maksimum ideal skor minimum ideal)

Tabel 2. Distribusi Sampel Penelitian

\begin{tabular}{lcc}
\hline \multirow{2}{*}{ Mahasiswa } & Populasi & Sampel \\
\cline { 2 - 3 } & $\mathbf{X}$ & XI \\
\hline Semester I & 164 & 68 \\
Semester II & 112 & 47 \\
Semester IV & 121 & 50 \\
Semester VI & 81 & 34 \\
\hline \multicolumn{1}{c}{ Total } & $\mathbf{4 7 8}$ & $\mathbf{1 9 9}$ \\
\hline
\end{tabular}

\section{HASIL DAN PEMBAHASAN}

Data safety riding pada mahasiswa Program Studi PTM diperoleh berdasarkan tes tertulis pilihan ganda dengan hasil sebagai berikut:

Tabel 3. Rangkuman Data Safety Riding

\begin{tabular}{ccccccc}
\hline Variabel & N & Min & Maks & Mean & SD & Kategori \\
\hline Safety Riding & 199 & 15,00 & 33,00 & 24,78 & 3,36 & Sangat Tinggi \\
\hline
\end{tabular}

Tabel 3 menunjukan bahwa tingkat safety riding mahasiswa PTM dengan nilai rata-rata 24,78 dikategorikan sangat tinggi dengan nilai terendah 15,00, nilai tertinggi 33,00 dan standar deviasi 3,36. Deskripsi distribusi frekuensi data safety riding dibagi menjadi 5 kategori dihitung dari skor terendah ideal dan skor tertinggi ideal, yaitu 0-33 menggunakan rumus kriteria kurva normal. Distribusi frekuensi safety riding dapat dilihat sebagai berikut:

Tabel 4. Distribusi Frekuensi Safety Riding 


\begin{tabular}{|c|c|c|c|c|}
\hline \multirow{2}{*}{ No } & \multirow{2}{*}{ Interval } & \multirow{2}{*}{ Kategori } & \multicolumn{2}{|c|}{ Frekuensi } \\
\hline & & & Absolut & Relatif (\%) \\
\hline 1 & $0 \leq \mathrm{X}<8.23$ & Sangat rendah & 0 & 0 \\
\hline 2 & $8,23 \leq X<13,74$ & Rendah & 0 & 0 \\
\hline 3 & $13,74 \leq X<19,25$ & Sedang & 9 & 4,52 \\
\hline 4 & $19,25 \leq X<24,76$ & Tinggi & 89 & 44,72 \\
\hline 5 & $24,76 \leq X \leq 33$ & Sangat tinggi & 101 & 50,75 \\
\hline & Total & & 199 & 100,00 \\
\hline
\end{tabular}

Tabel 4 menunjukan bahwa tidak ada responden yang memiliki pengetahuan safety riding dalam kategori sangat rendah dan rendah. Sebanyak 9 responden atau 4,52\% memiliki pengetahuan safety riding dalam kategori sedang. Sebanyak 89 responden atau $44,72 \%$ memiliki pengetahuan safety riding dalam kategori tinggi. Sebanyak 101 responden atau $50,75 \%$ memiliki pengetahuan safety riding dalam kategori sangat tinggi.

Berdasarkan hasil penelitian dapat diketahui bahwa tingkat pengetahuan berkendara yang aman mahasiswa PTM UST dengan nilai rata-rata 24,78, nilai minimal 15 dan nilai maksimal 33 dikategorikan sangat tinggi. Semua indikator tentang cara berkendara yang aman seperti mengetahui marka jalan dan cara berkendara yang baik sesuai dengan ketentuan berlalu lintas, mengetahui arti rambu-rambu lalu lintas, mengetahui berbagai perlengkapan yang digunakan/dibawa saat berkendara dan mengetahui perlengkapan dan pemeriksaan sepeda motor agar sepeda motor memenuhi persyaratan teknis dan laik jalan masuk dalam kategori sangat tinggi.

Penelitian yang dilakukan oleh Setyo Dwi Widiyastuti dan Neneng Trisnawati (2018), didapatkan hasil bahwa mayoritas mahasiswa STIKES Indramayu yaitu 88 atau $48 \%$ memiliki pengetahuan yang cukup (e-journal-akbidjemberac.id). Berbeda dengan penelitian yang dilakukan oleh Raditya Ariwibowo (2013) didapatkan hasil mayoritas pengendara ojek sepeda motor di kecamatan Banyumanik yaitu 26 responden (56,5\%) memiliki pengetahuan yang kurang (Jurnal Kesehatan Masyarakat, 2013 volume 2).

Hasil penelitian ini menunjukan bahwa tingkat pengetahuan berkendara yang aman (safety riding) bagi mahasiswa PTM UST sudah bagus karena masuk dalam kategori sangat tinggi, jika pengetahuan tentang berkendara yang aman sudah baik seharusnya di imbangi dengan praktik berkendaranya karena memiliki pengetahuan yang sangat tinggi belum tentu menerapkan praktik safety riding saat berkendara. Sejalan dengan penelitian yang dilakukan 
oleh Yugo Fajar Suasana (2014), didapatkan hasil bahwa 94\% mahasiswa Universitas Jember memiliki pengetahuan tentang safety riding dalam kategori tinggi dan tidak terdapat hubungan antara pengetahuan dengan praktik safety riding karena nilai $\mathrm{p}=0,460>\alpha=0,05$ (http://repository.unej.ac.id/handle/ 123456789/21033)

Konsumsi bahan bakar di Indonesia terus meningkat setiap tahunnya. Direktur pemasaran Pertamina, M Iskandar mengatakan total konsumsi semua produk BBM pada semester pertama tahun 2017 mencapai 32,6 juta kilo liter (kl), sementara konsumsi pada tahun 2016 sebesar 31,7 juta kilo liter (kl) untuk semua produk BBM (http://industri.bisnis.com/read/20170816/44/681587/konsumsi-bbmparuh_pertama2017memben).

Ditengah konsumsi bahan bakar dan harga bahan bakar yang kian meningkat, pengetahuan tentang berkendara secara ekonomis (eco riding) harus diperhatikan untuk dapat lebih efisien dalam menggunakan bahan bakar. Untuk dapat berkendara secara ekonomis maka seharusnya pengendara sepeda motor mengetahui tentang cara berkendara ekonomis seperti, mengetahui cara berkendara yang dapat menghemat penggunaan konsumsi bahan bakar dan mengetahui berbagai pemeriksaan dan perbaikan sepeda motor agar penggunaan bahan bakar lebih efisien.

Data eco riding pada mahasiswa Program Studi PTM diperoleh berdasarkan tes tertulis pilihan ganda dengan hasil sebagai berikut:

Tabel 5. Rangkuman Data Eco Riding

\begin{tabular}{ccccccc}
\hline Variabel & N & Min & Maks & Mean & SD & Kategori \\
\hline Eco Riding & 199 & 2,00 & 8,00 & 6,85 & 1,41 & Sangat Tinggi \\
\hline
\end{tabular}

Tabel 5 menunjukan bahwa tingkat eco riding mahasiswa PTM dengan nilai rata-rata 6,85 dikategorikan sangat tinggi dengan nilai terendah 2,00, nilai tertinggi 8,00 dan standar deviasi 1,41. Deskripsi distribusi frekuensi data eco riding dibagi menjadi 5 kategori dihitung dari skor terendah ideal dan skor tertinggi ideal, yaitu 0-8 menggunakan rumus kriteria kurva normal. Distribusi frekuensi eco riding dapat dilihat sebagai berikut:

Tabel 6. Distribusi Frekuensi Eco Riding

\begin{tabular}{|c|c|c|c|}
\hline No & Interval & Kategori & Frekuensi \\
\hline
\end{tabular}




\begin{tabular}{rccrr}
\hline & & & Absolut & Relatif (\%) \\
\hline 1 & $0 \leq \mathrm{X}<1,99$ & Sangat rendah & 0 & 0 \\
2 & $1,99 \leq \mathrm{X}<3,332$ & Rendah & 4 & 2,01 \\
3 & $3,332 \leq \mathrm{X}<4,668$ & Sedang & 12 & 6,03 \\
4 & $4,668 \leq \mathrm{X}<6,01$ & Tingi & 51 & 25,63 \\
5 & $6,01 \leq \mathrm{X} \leq 8$ & Sangat tinggi & 132 & 66,33 \\
\hline & & $\mathbf{1 9 9}$ & $\mathbf{1 0 0 , 0 0}$
\end{tabular}

Tabel 6 menunjukan bahwa tidak ada responden yang memiliki pengetahuan eco riding dalam kategori sangat rendah. Sebanyak 4 responden atau 2,01\% memiliki pengetahuan eco riding dalam kategori rendah. Sebanyak 12 responden atau 6,03\% memiliki pengetahuan eco riding dalam kategori sedang. Sebanyak 51 responden atau 25,63\% memiliki pengetahuan eco riding dalam kategori tinggi. Sebanyak 132 responden atau 66,33\% memiliki pengetahuan eco riding dalam kategori sangat tinggi

Indikator tentang cara berkendara ekonomis seperti mengetahui cara berkendara yang dapat menghemat penggunaan bahan bakar masuk dalam kategori sangat tinggi dan indicator mengetahui berbagai pemeriksaan dan perbaikan sepeda motor agar penggunaan bahan bakar lebih efisien masuk dalam kategori tinggi. Meskipun hasil penelitian ini menunjukan bahwa rata-rata nilai pengetahuan berkendara yang ekonomis mahasiswa PTM dalam kategori sangat tinggi, masih terdapat mahasiswa yang masuk dalam kategori rendah sebanyak 4 mahasiswa atau 2,01\% dan kategori sedang sebanyak 12 mahasiswa atau 6,03\%. Prosentase mahasiswa yang masuk kategori rendah dan sedang memang hanya sedikit tetapi hal ini perlu diperhatikan dan dibenahi agar pengetahuan berkendara ekonomis mahasiswa yang termasuk dalam kategori rendah dan sedang dapat meningkat. Pengetahuan berkendara ekonomis dapat ditingkatkan melalui penyuluhan tentang cara berkendara yang ekonomis dari pihak yang terkait.

\section{SIMPULAN}

Berdasarkan hasil penelitian dan pembahasan dari penelitian ini, maka dapat ditarik simpulan sebagai berikut:

1. Tingkat kesadaran berkendara aman (safety riding) pada mahasiswa Program Studi Pendidikan Teknik Mesin Universitas Sarjanawiyata Tamansiswa dikategorikan sangat tinggi dengan nilai rata-rata 24,78 . 
2. Tingkat berkendara secara ekonomis (eco riding) pada mahasiswa Program Studi Pendidikan Teknik Mesin Universitas Sarjanawiyata Tamansiswa dikategorikan sangat tinggi dengan nilai rata-rata 6,85 .

\section{UCAPAN TERIMA KASIH}

Ucapan terima kasih disampaikan kepada pihak LP3M UST yang telah mendanai penelitian ini.

\section{DAFTAR PUSTAKA}

. (2010). Definisi dan penjelasan safety riding. Diperoleh 10 Februari 2017, dari http://jnc.000space.com/index.php?option=com_content $\&$ view=article \&id=51:definisi -dan-penjelasan-safety-riding \&catid=38:tips\&Itemid=50\&i=1

. (2016). Kamus Besar Bahasa Indonesia. Diperoleh 10 Februari 2017, dari https://kbbi.kemdikbud.go.id/Cari/Index

Akhmad David Casidy Rival, Anita Dewi P.S., dan Ismi Ragil Hartanti. (2015). Faktor risiko yang berhubungan dengan kecelakaan lalu lintas pada pengemudi bus P.O Jember Indah. Artikel Ilmiah Hasil Penelitian Mahasiswaa: Tidak diterbitkan

Arizona Online Defensive Driving. (2013). Driver Attitude and Behavior. Diperoleh 10 Februari 2017, dari www.arizonadriver.com.

BPS Provinsi D.I. Yogyakarta. (2015). Daerah Istimewa Yogyakarta dalam angka. Yogyakarta: Badan Pusat Statistik Provinsi D.I. Yogyakarta.

BPS. Proyeksi Penduduk Indonesia berdasar sensus 2010. (http:/www.bps.go.id) diakses pada tanggal 5 maret 2018

Eni Mahawati dan Jaka Prasetya. (2013). Pola interaksi determinan perilaku "safety riding" dalam upaya eliminasi gangguan kesehatan \& kecelakaan lalu lintas guna meningkatkan kualitas hidup generaasi muda. Laporan Penelitian Universitas Dian Nuswantoro Semarang: Tidak diterbitkan

Fitria Wulandari. (2015). Pemahaman pelajar tentang disiplin berlalu lintas (studi di SMK Kesehatan Samarinda). eJournal Sosiatri-Sosiologi, Vol 3, No. 3, 52-64.

Irwan. (2016). Pelanggaran lalu lintas yang sering terjadi di Jogja. Diperoleh 10 Februari 2017, dari http://www.lenterajogja.com/2016/02/pelanggaran-lalu-lintas-yang-sering.html. 
M.Iskandar. jumlah penggunaan bahan bakar. http://industri.bisnis.com/read/ 20170816/44/681587/ konsumsi-bbm-paruh-pertama-2017-membengkak/. Di akses tanggal 11 April 2018

Malayu Hasibuan. (2012). Manajemen sumber daya manusia. Jakarta: PT Bumi Aksara.

Marye Agung Kusmagi. (2010). Selamat berkendara di jalan raya. Jakarta: Raih Asa Sukses.

Modifikasi. 15 tips agar motor irit bahan bakar. http://www.modifikasi.co.id/2013/15. Di akses tanggal 25 Mei 2018

Otomotifnet. panduan eco riding. https://otomotifnet.gridoto.com/read/02114923/. Di akses tanggal 10 Mei 2018

Presiden. (1993). Peraturan Pemerintah Republik Indonesia Nomor 43 Tahun 1993, tentang prasarana dan lalu lintas jalan.

Raditya Ariwibowo. 2013. Hubungan Antara Umur, Tingkat Pendidikan, Pengetahuan, Sikap terhadap Praktik Safety Riding Awareness Pada Pengendara Ojek Sepeda Motor Di Kecamatan Banyumanik. http://ejournals1.undip.ac.id/index .php/jkm. Di akses tanggal 29 September 2018.

Republik Indonesia. (2009). Undang-Undang Nomor 22 Tahun 2009, tentang lalu lintas dan angkutan jalan.

Setyo Dwi Widiyastuti dan Neneng Trisnawati. 2018. Gambaran Pengetahuan Dan Sikap Tentang Keselamatan berkendara (Safety Riding) Pada Mahasiswa STIKes Indramayu. e-journal-akbidjemberac.id. Di akses tanggal 29 September 2018.

Sukarsi Rusti dan Rezeki Mulia Falaah. (2016). Praktik safety riding pada pelajar di wilayah kerja polres padang panjang. Jurnall Human Care, Vo 1, No. 3. 